\title{
Do general practitioners miss dementia in elderly patients?
}

\author{
D W O'Connor, P A Pollitt, J B Hyde, C P B Brook, B B Reiss, M Roth
}

\begin{abstract}
General practitioners and community nurses were asked to rate the likelihood of dementia for each of their elderly patients. Cases of dementia were identified by research psychiatrists using the Cambridge mental disorders of the elderly examination (CAMDEX), a new structured diagnostic interview. General practitioners correctly identified dementia as at least a possibility in 121 of the 208 cases found. Nevertheless, they mistakenly rated as demented several patients suffering from functional psychiatric disorders, in particular depression. Community nurses correctly identified dementia as at least a possibility in 64 of the 74 demented patients known to them, but they incorrectly suspected dementia in a greater proportion of instances. Both general practitioners and families appeared to have low expectations of what general practice has to offer demented elderly people.

General practitioners should take the initiative in diagnosing dementia in very elderly patients who show signs of the condition. In some cases it may be secondary to treatable disorders, and in others all that may be required are understanding, support, and advice to families.
\end{abstract}

\section{Introduction}

How accurate are general practitioners in recognising dementia in their elderly patients? In a frequently cited study by Williamson and colleagues 200 patients in three Scottish general practices were assessed by a geriatrician and a psychiatrist. ${ }^{1}$ Later their diagnoses were compared with information taken from the general practitioners' medical records and from interviews with them about each of their patients. The general practitioners were said to be aware of only seven of the 48 cases of dementia identified by the investigating team.

The findings of Williamson et al must be interpreted cautiously. Fifty five of the 200 patients assessed were judged to be demented, 39 of them mildly so. This is nearly three times the rate found in this age group in most other prevalence studies. ${ }^{2}$ The methods used to detect mild dementia-namely, a semistructured interview and a brief cognitive test - were inadequate by modern research standards ${ }^{3}$ and it seems highly likely that the general practitioners' diagnoses were judged against a false standard.

Parsons found a very much higher recognition rate in a study of the mental health of 288 residents of Swansea aged 65 and over. ${ }^{4}$ Each subject was interviewed at length and the assessment included a brief cognitive test and a discussion with a relative. Ten cases of dementia were identified, giving a plausible prevalence in this age group of $3.5 \%$. General practitioners were asked in a postal survey which patients included in the study had a history of "mental or emotional illness, including senile mental failure." They were aware of some sort of mental disorder in six of the 10 cases.
The difference in findings between these two studies almost certainly reflects more on the methods used than on the diagnostic acumen of the doctors concerned. We recently conducted a study of the prevalence of dementia in Cambridge. As part of this study we were able to compare general practitioners' and community nurses' judgments with diagnoses made by using a new diagnostic interview.

\section{Subjects and methods}

The names of all patients aged 75 and over on 1 April 1986 were taken from the age-sex registers of six group practices in Cambridge city. A further one in three names were sampled from a seventh practice to make up the numbers required for a later part of the project. All the practices were accredited for training.

Patients were asked through their doctors to take part in a screening interview which inquired into personal details, family contact, and health and concluded with the mini-mental state examination (MMSE). ${ }^{5}$ This brief, cognitive examination comprises tests of orientation, attention, language, and recall. It is acceptably reliable and valid as a screening test for cognitive impairment ${ }^{56}$ and has been used extensively in community studies in the United States. ${ }^{7}$

Respondents who scored 23 or less on the minimental state examination out of a maximum score of 30 , together with a one in three sample of those who scored 24 or 25 , were assessed in more detail by using the Cambridge mental disorders of the elderly examination. ${ }^{8}$ This examination (CAMDEX) is a lengthy diagnostic interview made up of a mental state examination, medical and psychiatric history, neuropsychological testing, and a brief physical examination. It includes an interview with an informant, usually a close relative, to establish whether there has been any change in cognition, personality, and behaviour. Dementia was diagnosed only when operational criteria appended to the examination protocol were satisfied. In addition to the Cambridge mental disorders of the elderly examination, relatives were asked to complete rating scales of the elderly persons' need for help in activities of daily living ${ }^{9}$ and of the strain they felt in providing care. ${ }^{10} \mathrm{~A}$ proportion of relatives were interviewed in detail about their experiences.

General practitioners and community nurses were asked to mark on a list of all their patients which ones they considered to be definitely not demented, possibly demented, or definitely demented, but only those assessed with the Cambridge mental disorders of the elderly examination are considered here. The medical records of all those given the examination were reviewed later. Notes were made of their medical and psychiatric histories, referrals to the psychogeriatric service, and number of consultations made in the 12 months before the interview.

Two groups of patients were excluded from the following analysis. Those in long stay hospitals were not included, as we thought it unreasonable to ask doctors and nurses to assess people who were no longer 
their responsibility. Another group of patients were diagnosed as having minimal dementia. This is a new, unvalidated category and it would be inappropriate to include cases in a study of the rightness or wrongness of diagnosis.

\section{Results}

Of the 2889 elderly people listed in the age-sex registers, 2616 were screened between 1 April 1986 and 31 March 1987, giving a contact rate of $91 \%$. There were 207 refusals, 52 patients could not be contacted despite repeated visits and telephone calls, and 14 were too ill to take part.

Of the 657 patients chosen for further investigation on the basis of their mini-mental state examination scores, 532 were assessed by the Cambridge mental disorders of the elderly examination. The contact rate in the second part of the study was therefore $81 \%$ and the contact rate overall $74 \%(91 \% \times 81 \%)$. Eighty two of the patients selected refused the Cambridge mental disorders of the elderly examination, 21 had died, nine could not be contacted, six spoke such poor English that assessment was impossible, and seven were overlooked in error.

Only 12 of the 207 patients $(6 \%)$ who refused the screening interview were thought by their doctors to be possibly or definitely demented compared with 392 of the $2616(15 \%)$ who agreed to take part. Similarly, only seven of the $82(9 \%)$ who refused the Cambridge mental disorders of the elderly examination were thought to be possibly or definitely demented compared with 106 of the $532(20 \%)$ who were assessed.

In all, 88 patients were excluded. Twenty two had been resident in long stay hospital wards for 1-11 years (mean 3 years), 48 were said to be minimally demented, and ratings were missing for 18. This left 444 patients available for analysis. Of these, 208 satisfied the Cambridge mental disorders of the elderly examination criteria for dementia; 96 cases were graded as mild, 85 as moderate, and 27 as severe. The overall prevalence of dementia in this particular age group was $10 \cdot 7 \%$ after adjusting for sampling of those scoring 24 or 25 on the mini-mental state examination.

General practitioners were able to rate the likelihood of dementia in 370 of the $444(83 \%)$ patients available for analysis. They considered that they were unable to make an informed judgment about the remaining 74 . These 74 patients were included in the analysis under the general practitioners' rating of "not demented"that is, if dementia was found to be present the doctors were judged to have been unaware of it. Thirty nine of these 74 patients were diagnosed as cognitively intact, 15 as mildly demented, 16 as moderately demented, and four as severely demented.

General practitioners correctly identified (that is, they rated as possibly or definitely demented) 48 of the 96 patients found to be mildly demented, 52 of the 85 found to be moderately demented, and 21 of the 27 found to be severely demented (table I). Thus they correctly identified $58 \%$ of all cases (121/208) and $65 \%$

TABLE I-Relation between general practitioners' ratings of dementio and diagnoses based on Cambridge mental disorders of the elderly examination $(n=444)$

\begin{tabular}{lcccc}
\hline $\begin{array}{l}\text { Diagnosis based on } \\
\text { Cambridge mental } \\
\text { disorders of the elderly } \\
\text { examination }\end{array}$ & \multicolumn{3}{c}{ General practitioners ratings } & \\
\cline { 2 - 4 } & $\begin{array}{c}\text { Not } \\
\text { demented }\end{array}$ & $\begin{array}{c}\text { Possibly } \\
\text { demented }\end{array}$ & $\begin{array}{c}\text { Definitely } \\
\text { demented }\end{array}$ & Total \\
\hline Not demented & 185 & 40 & 11 & 236 \\
Mild dementia & 48 & 27 & 21 & 96 \\
Moderate dementia & 33 & 21 & 31 & 85 \\
Severe dementia & 6 & 3 & 18 & 27 \\
\hline Total & 272 & 91 & 81 & 444 \\
\hline
\end{tabular}

of patients with moderate or severe dementia (73/112). When only those patients rated by the general practitioners as definitely demented were considered they correctly identified $21(22 \%)$ patients with mild dementia, $31(36 \%)$ with moderate dementia, and $18(67 \%)$ with severe dementia.

Patients whose dementia was recognised by the general practitioners were compared with those whose dementia was not recognised in terms of their ability to perform simple activities of daily living, the strain reported by the relatives caring for them, and the number of times they had been seen by their doctor in the previous 12 months (table II). There were too few

TABLE II - Mean scores of patients whose dementia was known and not known on rating scales of dependence in activities of daily living and of carer strain and mean numbers of consultations in previous year

\begin{tabular}{|c|c|c|c|c|c|c|c|}
\hline & \multicolumn{3}{|c|}{$\begin{array}{c}\text { Mild } \\
\text { dementia }\end{array}$} & \multicolumn{3}{|c|}{$\begin{array}{l}\text { Moderate } \\
\text { dementia }\end{array}$} & \multirow[b]{2}{*}{ Value } \\
\hline & $\begin{array}{l}\text { Maxi- } \\
\text { mum } \\
\text { score }\end{array}$ & $\begin{array}{c}\text { Not } \\
\text { known } \\
(n=48\end{array}$ & $\begin{array}{l}\text { Known } \\
(n=48)\end{array}$ & Value $^{\mathrm{p}}$ & $\begin{array}{c}\text { Not } \\
\text { known } \\
(n=33\end{array}$ & $\begin{array}{l}\text { Known } \\
(\mathrm{n}=52)\end{array}$ & \\
\hline $\begin{array}{l}\text { Activities of daily } \\
\text { living }\end{array}$ & 35 & $9 \cdot 9$ & $14 \cdot 3$ & 0.01 & $19 \cdot 6$ & $19 \cdot 9$ & 0.44 \\
\hline $\begin{array}{l}\text { Informant strain } \\
\text { Consultations in past }\end{array}$ & 13 & $6 \cdot 2$ & $7 \cdot 5$ & $0 \cdot 24$ & $9 \cdot 0$ & $12 \cdot 2$ & 0.04 \\
\hline $\begin{array}{l}\text { year } \\
\text {. }\end{array}$ & - & 4.5 & $7 \cdot 4$ & 0.0003 & $6 \cdot 4$ & $10 \cdot 2$ & 0.01 \\
\hline
\end{tabular}

*Mann-Whitney U test

cases of unrecognised severe dementia for analysis, and this group was therefore excluded. Inability to perform simple activities contributed to recognition only in the mildly demented group, and the strain experienced by relatives contributed to recognition only in the moderately demented group. The one factor which contributed to recognition to a significant degree in both groups was frequency of consultation; general practitioners more commonly recognised dementia in the patients they had seen most often in the previous year.

Community nurses were in contact with only 124 of the patients assessed by the Cambridge mental disorders of the elderly examination. They correctly identified (that is, they rated as possibly or definitely demented) 19 of the 27 patients found to be mildly demented, 31 of the 32 found to be moderately demented, and 14 of the 15 found to be severely demented (table III). Thus they correctly identified

TABLE III -Nurses' ratings of dementia compared with diagnoses based on Cambridge mental disorders of the elderly examination $(n=$ 124)

\begin{tabular}{|c|c|c|c|c|}
\hline \multirow{2}{*}{$\begin{array}{l}\text { Diagnosis based on } \\
\text { Cambridge mental } \\
\text { disorders of the elderly } \\
\text { examination }\end{array}$} & \multicolumn{3}{|c|}{ Nurses' ratings } & \multirow[b]{2}{*}{ Total } \\
\hline & $\begin{array}{c}\text { Not } \\
\text { demented }\end{array}$ & $\begin{array}{c}\text { Possibly } \\
\text { demented }\end{array}$ & $\begin{array}{l}\text { Definitely } \\
\text { demented }\end{array}$ & \\
\hline Not demented & 27 & 16 & 7 & 50 \\
\hline Mild dementia & 8 & 9 & 10 & 27 \\
\hline Moderate dementia & 1 & 10 & 21 & 32 \\
\hline Severe dementia & 1 & 1 & 13 & 15 \\
\hline Total & 37 & 36 & 51 & 124 \\
\hline
\end{tabular}

$86 \%$ of all cases $(64 / 74)$ and $96 \%$ of patients with moderate or severe dementia (45/47). They rated as definitely demented 10 of the 27 patients with mild dementia, 21 of the 32 with moderate dementia, and 13 of the 15 with severe dementia.

As the nurses were in contact with only 124 patients, comparison of the doctors' and nurses' recognition rates was restricted to this smaller group. Of the 27 mildly demented patients in this group, doctors rated 20 and nurses 19 as possibly or definitely demented; of the 32 patients with moderate dementia, doctors rated 23 and nurses 31 as possibly or definitely demented; and of the 15 patients with severe dementia, doctors rated 12 and nurses 14 as possibly or definitely demented. 
Of the 236 low scorers on the mini-mental state examination who were subsequently shown to be cognitively intact, 51 were incorrectly rated by the doctors as possibly or definitely demented, giving a misclassification rate of $22 \%$ in this group. Seventeen patients were found to be suffering from functional psychiatric disorders. Misclassified diagnoses included nine cases of depressive illness, five of personality disorder, and one each of anxiety disorder, paranoid disorder, organic personality disorder, and chronic schizophrenia. Four of the nine depressed patients had a past history of mood disturbance. Seven patients who were not psychiatrically disturbed were described by the interviewers using the Cambridge mental disorders of the elderly examination as "odd" or "difficult"; four were frail, deaf, or blind; and four were dysphasic or dysarthric. The rest showed no obvious abnormality.

Misclassification rates were much lower (5\%) when only patients rated as definitely demented were considered. There were 11 such patients, two of whom were diagnosed as having depressive illnesses and two as having personality disorders. One had severe Parkinson's disease and a history of acute confusional states.

The community nurses misclassified as possibly or definitely demented 21 of the 47 low scoring, cognitively intact patients in the small group of 114 known to both them and the doctors. By contrast, doctors misclassified 15 of these 47 patients. The nurses' incorrect diagnoses included seven cases of depressive illness and one each of chronic schizophrenia, chronic alcohol abuse without cognitive impairment, and personality disorder. A further five patients were frail, deaf, or blind and one was dysphasic. The rest seemed normal. Of the seven patients whom the nurses misclassified as definitely demented, three were depressed, one was a chronic schizophrenic, and one had a personality disorder.

The principal carers of 73 demented patients living in the community were interviewed in detail. Only six of the 24 caring for mildly demented relatives had discussed memory failure and its attendant problems with their general practitioners compared with 18 of the 44 caring for moderately demented relatives and four of the five caring for severely demented relatives.

Referral rates to the psychogeriatric services increased with the progression of dementia. Five of the 236 non-demented patients, three of the 96 mildly demented patients, 15 of the 85 moderately demented patients, and nine of the 27 severely demented patients had been seen at some time by the psychogeriatric service on domiciliary visits, as outpatients, or during admissions to hospital.

\section{Discussion}

The methods used to gauge doctors' and nurses' knowledge of their patients are contrived, and in all probability we have underestimated rather than overestimated their diagnostic accuracy. Doctors were asked to provide ratings for all their patients, whether they were regular attenders or not. Naturally, their ratings were more accurate for patients whom they saw more frequently. They were asked to rate only the likelihood of dementia. As a result they may have rated cognitively intact patients as "possibly demented" (that is "unlikely to be demented but the possibility cannot be excluded") while knowing full well that depression, personal inadequacy, or physical frailty was a more probable cause of patients' problems. In addition, only patients who scored less than 26 out of 30 on the mini-mental state examination were assessed with the Cambridge mental disorders of the elderly examination. Had we used this second examination to assess those scoring between 27 and 30, nearly all of whom would have been cognitively intact, the proportion of patients incorrectly classified as demented would have been very much lower.

General practitioners appear to recognise dementia more frequently than Williamson et al suggested in $1964 .{ }^{\prime}$ Clinical practice has improved over the past 20 years, especially in geriatrics. Nevertheless, we strongly suspect that Williamson et al judged the doctors concerned against a false standard. Moreover, we believe that their findings in relation to both dementia and depression may need to be re-evaluated. Williamson et al reported that general practitioners were aware of depression in only five of the 21 cases identified. By contrast, MacDonald found that general practitioners in south London correctly identified 56 of the 68 elderly patients who were high scorers on a depression rating scale." The problem was not that doctors failed to recognise depression but that, having recognised it, they failed to take any action.

General practitioners' ability to recognise mild dementia as at least a possibility in half the cases that we identified was surprising. Few appeared to make even occasional use of formal tests of orientation and memory. Clearly, they were alerted in some instances by reports from relatives of failing memory and disturbed behaviour, but this accounted for only some of their successes. A large proportion of the elderly people whom we interviewed had been under the care of the same doctor for many years. This continuity of care puts doctors in an excellent position to note deterioration in mental state. Were they regularly to apply brief cognitive tests, which take only a couple of minutes, and to question relatives about changes in memory, intellect, and behaviour their diagnostic accuracy would improve considerably.

Most dementias in the over 75s are of the Alzheimer type or due to vascular disease, ${ }^{2}$ and only exceptionally are expensive investigations warranted. The very elderly, however, are not immune from dementia secondary to many correctable medical or surgical conditions (for example, chronic subdural haematomas). The important point is that cognitive impairment due to these causes is reversible only if detected and treated at an early stage. Such cases can be identified only if a brief history is taken together with an examination of mental state and physical condition whenever dementia is suspected. Nevertheless, because demented patients rarely complain of failing intellect - owing to lack of insight or fear of being "sent away"-and because families commonly present for help only when they have reached the limits of their endurance ${ }^{12}$ doctors will need to take the initiative.

Demented elderly people are disproportionately heavy users of hospital services. ${ }^{13}$ They are also at increased risk of acute confusional states due to infection and treatment with drugs, including anaesthesia. ${ }^{14}$ We noted that very few letters of referral to clinics or admitting officers made any reference to dementia, even when general practitioners were aware of it. This information is essential. Demented elderly people, who may appear to be perfectly normal on brief contact, have difficulty in understanding questions, giving accurate replies, remembering instructions, and following the sort of complex procedures entailed in testing eyesight and hearing. Acute confusional states commonly arise against a background of mild to moderate dementia. If they were given some warning hospital staff could take preventive action. Is it possible that general practitioners avoid referring to dementia for fear that patients may be stigmatised?

Both general practitioners and nurses seem to have difficulty in differentiating dementia from other psychiatric disorders. Physically frail or "odd" elderly people who are mistakenly thought to be demented are unlikely to come to any harm, as doctors fail to act on 
their suspicions. Depressive illnesses, however, are potentially treatable. Early dementia is sometimes accompanied by depression, and a few seriously depressed elderly people are so confused and retarded that they may give the impression of being demented. We, however, had no difficulty in diagnosing depression in the patients seen in this study. All stood to benefit from psychological support and a trial of antidepressant agents. An inquiry into mood, capacity for pleasure, feelings about the future, appetite, and sleep is usually enough to settle the diagnosis.

Sixty per cent of the demented patients (125/208) were cared for at home by their families. Most demented elderly people want to stay at home for as long as possible and most families contemplate admission to care only as a last resort. Nevertheless, only a quarter of those caring for mildly impaired relatives and two fifths of those caring for moderately impaired relatives had raised the subject of dementia with their general practitioners. Many of the carers who laboured under considerable difficulties adopted a fatalistic approach, thinking that there was little that doctors (or anybody else) could do to help.

Do general practitioners avoid discussing dementia with families? If doctors think of dementia as leading inevitably to a state of incoherence and incontinence they might prefer to say nothing than risk spreading gloom and despondency. Yet only a proportion of sufferers reach this advanced state. We found time and again that relatives benefited from talking about their difficulties, and those who felt able to talk to their doctors valued this greatly. Once again doctors will need to take the initiative in many cases. Understanding, support, and advice about accommodation and social services may be all that are required.

Community nurses correctly recognised an impressive proportion of cases of dementia, and their lack of training in differential diagnosis doubtless explained their tendency to suspect dementia when it was not actually present. Williamson found that nurses given extra training were well able to detect mental disorders in vulnerable elderly people. ${ }^{15}$ Community nurses spend much of their time caring for the very old and frail, who are at risk not just of dementia but also of functional mental disorders, in particular depression. ${ }^{16}$ In addition, relatives may find it easier to talk to them about worries that are not strictly "medical." Nurses may therefore have an important part to play in identifying cases, in alerting doctors to patients likely to benefit from more detailed assessment and treatment, and in supporting families.

The Hughes Hall Project for Later Life is funded by the Charles Wolfson Charitable Trust. We thank the general practitioners and nurses for the help and trust they extended to us; Drs J Fellows and N Miller for help with interviews in the Cambridge mental disorders of the elderly examination; Mrs R Coe for help with computing; and Dr B M Herbertson for support and advice.

1 Williamson J, Stokoe IH, Gray S, et al. Old people at home: their unreported needs. Lancet 1964;i:1117-20

2 Kay DWK, Bergmann K. Epidemiology of mental disorders among the aged in the community. In: Birren JE, Sloane RB, eds. Handbook of mental health and ageing. New Jersey: Prentice-Hall, 1980:34-56

3 Huppert FA, Tym E. Clinical and neuropsychological assessment of dementia. BrMed Bull 1986;42:11-8.

4 Parsons PL. Mental health of Swansea's old folk. British fournal of Preventive and Social Medicine 1965;19:43-7.

5 Folstein MF, Folstein SE, McHugh PR. "Mini-mental state": a practical method for grading the cognitive state of patients for the clinician. method for grading the cognitive

6 Anthony JC, LeResche L, Niaz U, Von Korff MR, Folstein MF. Limits of the "mini-mental state" as a screening test for dementia and delirium among "mini-mental state" as a screening test for dem

7 Folstein M, Anthony JC, Parhad I, Duffy B, Gruenberg EM. The meaning of cognitive impairment in the elderly. $\mathcal{F}$ Am Geriatr Soc 1985;33:228-35.

8 Roth M, Tym E, Mountioy CQ, et al: CAMDEX: a standardised instrumen for the diagnosis of mental disorder in the elderly with special reference to the early detection of dementia. Br $\mathcal{A}$ Psychiatry 1986;149:698-709.

9 Lawton MP, Brody EM. Assessment of older people: self-maintaining and instrumental activities of daily living. Gerontologist 1969;9:179-86.

10 Gilleard CJ. Living with dementia: community care of the elderly mentally infirm. London: Croom Helm, 1984:123.

11 MacDonald AJD. Do general practitioners "miss" depression in elderly patients? BrMed f 1986;292:1365-7.

12 Isaacs B. Geriatric patients: do their families care? BrMed f 1971;iv:282-6.

13 Kay DWK, Bergmann K, Foster EM, McKechnie AA, Roth M. Mental illness and hospital usage in the elderly: a random sample followed up. Compr Psychiatry 1970;11:26-35.

14 Evans JG. The psychiatric aspects of physical disease. In: Levy R, Post F, eds. The psychiatry of late life. Oxford: Blackwell Scientific, 1982:114-42.

15 Williamson J. Screening, surveillance and case-finding. In: Arie T, ed. Healt care of the elderly. London: Croom Helm, 1981:194-213.

16 Cooper B. Mental illness, disability and social conditions among old people in Mannheim. In: Hafner H, Moschel G, Sartorius N, eds. Mental health of the elderly. Berlin: Springer-Verlag, 1986:35-45.

(Accepted 23 August 1988)

\section{ANY QUESTIONS}

What are the indications for and side effects of treatment with goserelin for a patient with carcinoma of the prostate?

The standard treatment for symptomatic advanced prostatic cancer is androgen deprivation. This can be achieved either by surgical castration or by medical means. Goserelin is a superanalogue of luteinising hormone releasing hormone produced under the trade name Zoladex by ICI Pharmaceuticals and is available as a monthly depot injection administered subcutaneously. In a large, detailed multicentre trial undertaken by the British Prostate Group comparing goserelin with orchidectomy no significant difference was found between the two treatment arms.' Similar studies have been performed with other analogues of luteinising hormone releasing hormone confirming their efficacy in advanced prostatic cancer. ${ }^{2}$ Goserelin should therefore be used in a similar way to orchidectomy as palliation for men with symptomatic advanced prostatic cancer.

The physiological effects of analogues of luteinising hormone releasing hormone such as goserelin are similar to those of orchidectomy. ${ }^{1}$ Impotence develops in $85 \%$ of men who are potent before treatment, and $70 \%$ of these men report loss of or diminution in libido. Only $40 \%$ of men, however, admitted to the studies were potent at entry. The incidence of hot flushes was roughly $60 \%$ in both groups. Tumour flare occurs in a small proportion of patients on starting goserelin treatment owing to the initial surge of testosterone before pituitary down regulation produces medical castration ( $6 \%$ in this series). There is a theoretical risk of an exacerbation of the disease, which may be particularly dangerous if ureteric obstruction or incipient spinal cord compression is present. This can be prevented by pretreatment with oestrogens ${ }^{3}$ or antiandrogens such as cyproterone acetate. ${ }^{4}$
It also has been suggested that as one fifth of men with prostatic cancer treated with hormones do not respond agents such as goserelin could be used to identify responders and non-responders before more invasive treatments such as orchidectomy are used.-J C GINGELL, consultant urologist, and D A GILLATT, research fellow, Bristol

1 Peeling WB. A phase III trial comparing ICI 118630 (Zoladex) with orchidectomy in the management of advanced prostatic cancer. $\mathrm{Br} f$ Urol (in press).

2 Parmar H, Edwards L, Phillips RH, Allen L, Lightman SL. Orchidectomy versus long acting D-Trp-6-LHRH in advanced prostatic cancer. Brf Urol 1987;59:248-54.

3 Stien BS, Smith JA. DES lead-in to use of luteinizing hormone releasing hormone analogs in the treatment of metastatic carcinoma of the prostate. Urology 1985;25:350.

4 Boccon-Gibod L, Laudat MH, Dugue MA, Steg A. Cyproterone acetate lead-in prevents initial rise of serum testosterone induced by luteinizing hormone-releasing hormone analogues in the treatment of metastatic carcinoma of the prostate. Eur Urol 1986;12:400-2.

Is the long term use of quinine sulphate (200-400 mg at night) for night cramps likely to be associated with any adverse effects?

Quinine can produce two types of adverse effect: allergic reactions, which occur rarely and include rashes, fever, thrombocytopenia, and asthma; and dose related toxic effects. The latter include tinnitus, headache, nausea, and visual disturbances. They are usually associated with higher doses than those used to treat nocturnal cramps. A few patients, however, seem to be particularly susceptible to quinine toxicity and may develop these toxic effects with prolonged use of low doses. This is rare, and the great majority of patients given quinine for nocturnal cramps experience no adverse effects. - LINDA BEELEY, consultant clinical pharmacologist, Birmingham

Reynolds JEF, ed. Martindale. The extra pharmacopoeia. 28th ed. London: The Pharmaceutical Press, 1982:404. 